\title{
Exercise Stress Echocardiography of the Pulmonary Circulation
}

\section{Limits of Normal and Sex Differences}

\author{
Paola Argiento, MD; Rebecca R. Vanderpool, PhD; Massimiliano Mulè, MD; \\ Maria Giovanna Russo, MD; Michele D'Alto, MD; Eduardo Bossone, MD; \\ Naomi C. Chesler, PhD; and Robert Naeije, MD
}

\begin{abstract}
Background: Exercise stress echocardiography has not been recommended in the diagnostic workup of pulmonary hypertension because of insufficient certainty about feasibility and limits of normal.

Methods: Doppler echocardiography pulmonary hemodynamic measurements were performed at a progressively increased workload in 56 healthy male and 57 healthy female volunteers aged 19 to 63 years. Mean pulmonary artery pressure (mPAP) was estimated from the maximal tricuspid regurgitation jet velocity. Cardiac index was calculated from the left ventricular outflow velocity-time integral. Pulmonary vascular distensibility $\alpha$ index, the percentage change of vessel diameter per mm Hg of mPAP, was calculated from multipoint mPAP-cardiac output (CO) plots.

Results: Peak exercise at $175 \pm 50 \mathrm{~W}$ was associated with an $\mathrm{mPAP}$ of $33 \pm 7 \mathrm{~mm} \mathrm{Hg}$ and a $\mathrm{CO}$ of $18 \pm 5 \mathrm{~L} / \mathrm{min}$. The slope of mPAP-CO relationships was $1.5 \pm 0.5 \mathrm{~mm} \mathrm{Hg} / \mathrm{L} / \mathrm{min}$, and the distensibility coefficient $(\alpha)$ was $1.3 \% \pm 1.0 \% / \mathrm{mm} \mathrm{Hg}$. Maximal workload and cardiac index were higher in men than in women $(P<.05)$, but mPAP-cardiac index relationships were not different. However, women had a higher $\alpha(1.6 \% \pm 1.3 \% / \mathrm{mm} \mathrm{Hg}$ vs $1.1 \% \pm 0.6 \% / \mathrm{mm} \mathrm{Hg}, P<.05)$. The average mPAP-cardiac index slope was higher and $\alpha$ lower in subjects $\geq 50$ years old. Upper limits of normal of mPAP at exercise were $34 \mathrm{~mm} \mathrm{Hg}$ at a $\mathrm{CO}<10 \mathrm{~L} / \mathrm{min}, 45 \mathrm{~mm} \mathrm{Hg}$ at a $\mathrm{CO}<20 \mathrm{~L} / \mathrm{min}$, and $52 \mathrm{~mm} \mathrm{Hg}$ at a $\mathrm{CO}<30 \mathrm{~L} / \mathrm{min}$. These values are in keeping with previously reported invasive measurements.

Conclusions: Exercise stress echocardiography of the pulmonary circulation is feasible and allows for flow-corrected definition of upper limits of normal. Women have a more distensible pulmonary circulation.

CHEST 2012; 142(5):1158-1165

Abbreviations: $\alpha=$ distensibility coefficient; $\mathrm{CO}=$ cardiac output; LAP $=$ left atrial pressure; $\mathrm{mPAP}=$ mean pulmonary artery pressure; $\mathrm{PAP}=$ pulmonary artery pressure; $\mathrm{PVR}=$ pulmonary vascular resistance; $\mathrm{sPAP}=$ systolic pulmonary artery pressure
\end{abstract}

$\mathbf{P}$ ulmonary hypertension has been defined previously as a mean pulmonary artery pressure $(\mathrm{mPAP})>25 \mathrm{~mm} \mathrm{Hg}$ at rest and $>30 \mathrm{~mm} \mathrm{Hg}$ during exercise..$^{1,2}$ Exercise measurements were withdrawn from the hemodynamic definition of pulmonary hypertension at an expert consensus conference held in 2008 in Dana Point. ${ }^{3}$ This decision was based mainly on an analysis of the reported invasive pulmonary hemodynamic studies in healthy subjects at exercise revealing uncertainty about the exact upper limits of normal. ${ }^{4}$ In the meantime, exercise-induced pulmonary arterial hypertension was validated as a clinical entity. ${ }^{5}$ Thus, a robust definition of the limits of normal of the pulmonary circulation at exercise would be of great relevance. However, for ethical and practical reasons, it is unlikely that a large number of rightsided heart catheterizations in healthy subjects will be reported in the near future. Therefore, there is currently interest in noninvasive exercise stress echocardiography of the pulmonary circulation. ${ }^{6}$

We previously reported a preliminary study on the feasibility of noninvasive echo-Doppler measurements of the normal pulmonary circulation at rest and at exercise. ${ }^{7}$ From multipoint mPAP-flow coordinates in 25 healthy adults, we recovered pulmonary vascular resistance (PVR) and distensibility calculations 
that were in good agreement with those of previously reported invasive studies. We, therefore, now extend these measurements to a larger number of healthy men and women to define limits of normal and thereby offer a potentially useful test for the screening of people who are asymptomatic or mildly symptomatic with diseases associated with pulmonary hypertension.

\section{Materials AND Methods}

One hundred twenty-four volunteers (62 women and 62 men) aged $37 \pm 13$ years (range, 18-63 years) with a height and weight of $173 \pm 9 \mathrm{~cm}$ and $70 \pm 11 \mathrm{~kg}$, respectively (body surface area, $1.8 \pm 0.2)$ gave an informed consent to the study, which was approved by the ethical committee of the Erasme University Hospital (No. P2011/101; Ref. Eudract/CCB: B406201110799, Brussels, Belgium). The subjects were nonsmokers and were free of any cardiovascular or lung disease. None had a family history of pulmonary hypertension. All were physically active, but none trained for $>5 \mathrm{~h}$ per week, and, thus, were not considered athletes. Baseline clinical examination and ECG were normal. Eleven volunteers were excluded because of echocardiography of insufficient quality. Thus, complete sets of measurements were obtained in 57 women and 56 men. Forty-two women were taking oral contraceptives.

A standard echocardiographic examination was performed at rest and during exercise as reported previously. ${ }^{7}$ The workload was increased by 20 to $30 \mathrm{~W}$ every 2 min until the maximal workload tolerated because of dyspnea and/or leg pain. Echocardiographic measurements were taken during the last minute of each workload. Doppler echocardiography was performed with a Vivid 7 ultrasound system (GE Healthcare) on a semirecumbent cycle ergometer (model $900 \mathrm{EL}$; Ergoline). The exercise table was tilted laterally by $20^{\circ}$ to $30^{\circ}$ to the left. Cardiac output (CO) was estimated from the left ventricular outflow tract cross-sectional area and pulsed Doppler velocity-time integral measurements. ${ }^{8}$ Systolic pulmonary artery pressure (sPAP) was estimated from a trans-tricuspid gradient calculated from the maximal velocity $(\mathrm{V})$ of continuous Doppler tricuspid regurgitation as $4 \times \mathrm{V}^{2}+5 \mathrm{~mm} \mathrm{Hg}$ assigned to right atrial pressure. ${ }^{9} \mathrm{mPAP}$ was calculated as $0.6 \times \mathrm{sPAP}+2 .{ }^{10}$ Left atrial pressure (LAP) was estimated from

Manuscript received January 10, 2012; revision accepted March 31, 2012.

Affiliations: From the Department of Cardiology (Drs Argiento, Russo, and D'Alto), Second University of Naples, Naples, Italy; the Clinical Division of Cardiology (Dr Mulè), Ferrarotto Hospital, University of Catania, Catania, Italy; the Department of Cardiac Surgery (Dr Bossone), IRCCS Policlinico San Donato, San Donato Milanese, Milan, Italy; the Department of Biomedical Engineering (Dr Chesler), University of Wisconsin-Madison, Madison, WI; and the Department of Physiology (Drs Vanderpool and Naeije), Faculty of Medicine, Free University of Brussels, Brussels, Belgium.

Drs Argiento and Vanderpool contributed equally to this article. Funding/Support: This work was supported by the National Institutes of Health [1R01HL105598 to NCC], the Funds for Cardiac Surgery [to R. N.], the Fonds de la Recherche Scientifique Médicale [3.4637.09 to R. N.], and the Bureau for International Relations and Cooperation [to R. R. V.].

Correspondence to: Robert Naeije, MD, Department of Physiology, Faculty of Medicine, Free University of Brussels, Erasme Campus CP 604, 808 Lennik Rd, 1070 Brussels, Belgium; e-mail: rnaeije@ulb.ac.be

(C) 2012 American College of Chest Physicians. Reproduction of this article is prohibited without written permission from the American College of Chest Physicians. See online for more details. DOI: $10.1378 /$ chest.12-0071 the ratio of Doppler mitral $\mathrm{E}$ flow-velocity wave and tissue Doppler mitral annulus flow $\mathrm{E}^{\prime}$ early diastolic velocity (ie, $\left.\mathrm{LAP}=1.9+1.24 \mathrm{E} / \mathrm{E}^{\prime}\right) .{ }^{11}$

The echocardiographic recordings were stored on optical disks and read in duplicate by blinded observers (P. A., M. D., and M. M.). We previously reported intraobserver variabilities for sPAP and CO estimates of $4.3 \%$ and $4.0 \%$ at rest and $8.2 \%$ and $7.7 \%$ at maximal exercise, respectively, and interobserver variabilities of sPAP and CO estimates of $1.9 \%$ and $4.9 \%$ at rest and $7.9 \%$ and $13.9 \%$ at maximal exercise, respectively. ${ }^{7}$

PVR was calculated as (mPAP - LAP)/CO. Multipoint mPAP-CO and mPAP-indexed CO (cardiac index) plots were tested for linearity, and linear regressions were calculated for pooled male and female measurements after Poon adjustment for individual variability. ${ }^{12}$ Each multipoint mPAP-CO plot was also fitted to the equation:

$$
m P A P=\frac{\left[(1+\alpha L A P)^{5}+5 \alpha R_{0}(C O)\right]^{\frac{1}{5}}-1}{\alpha}
$$

where $R_{0}$ is the total PVR at rest, to calculate a distensibility $\alpha$ index in percentage change in diameter per $\mathrm{mm} \mathrm{Hg}$ increase in transmural pressure. ${ }^{13}$ To investigate the effect of exercise on the distensibility index, a specific distensibility coefficient $(\alpha)$ index was calculated at rest ( $\alpha$-rest) as well as at peak exercise ( $\alpha$-peak).

Results are presented as mean $\pm \mathrm{SD}$. The statistical analysis consisted of least-squares linear regression calculations and Student $t$ tests after checking for normality of distributions using the D’Agostino skewness test. Nonnormal distributions were found in calculations of $\alpha$ and slopes of pressure-flow curves, so a Wilcoxon rank sum test was performed. $P<.05$ was considered significant. Limits of normal on slopes of mPAP-CO and mPAP-cardiac index were defined as mean -2 SD to mean +2 SD. Prediction bands (S-pred) were calculated based on a quadratic fit of the pooled pressure-flow data in MATLAB (The MathWorks, Inc), using the equation:

$$
S_{\text {pred }}(x)=\sqrt{s^{2}\left(1+\frac{1}{n}+\frac{(x-\bar{x})^{2}}{\sum\left(x_{i}-\bar{x}\right)^{2}}\right)}
$$

Statistical analysis was performed using R (R-project.org, version 2.13.0).

\section{RESUlTS}

Good-quality signals were available at all levels of exercise in all subjects. Because 11 subjects had been excluded at an initial echocardiographic evaluation, this corresponds to an $87 \%$ recovery rate of a complete exercise stress echocardiography of the pulmonary circulation in healthy adults.

\section{Pressure-Flow Relationships and Limits of Normal}

As shown in Table 1, peak exercise at an average of $175 \mathrm{~W}$ (men + women) was accompanied by a closeto-fourfold increase in $\mathrm{CO}$ and a doubling of mPAP. Exercise increased LAP by an average of $2 \mathrm{~mm} \mathrm{Hg}$ and did not affect PVR. Each mPAP-CO plot was well 
Table 1-Hemodynamic Measurements at Rest and at Peak Exercise in 56 Male and 57 Female Subjects

\begin{tabular}{|c|c|c|c|c|}
\hline \multirow[b]{2}{*}{ Measurement } & \multicolumn{2}{|c|}{ Men } & \multicolumn{2}{|c|}{ Women } \\
\hline & Rest & Peak Exercise & Rest & Peak Exercise \\
\hline mPAP, mm Hg & $15.5 \pm 2.6$ & $36.0 \pm 5.9$ & $15.1 \pm 2.9$ & $30.5 \pm 7.2^{\mathrm{a}}$ \\
\hline LAP, mm Hg & $7.9 \pm 1.2$ & $9.9 \pm 1.2$ & $8.1 \pm 1.4$ & $9.7 \pm 1.5$ \\
\hline $\mathrm{CO}, \mathrm{L} / \mathrm{min}$ & $5.9 \pm 1.4$ & $20.5 \pm 4.1$ & $4.6 \pm 0.8^{\mathrm{a}}$ & $14.8 \pm 3.2^{\mathrm{a}}$ \\
\hline Cardiac index, $\mathrm{L} / \mathrm{min} / \mathrm{m}^{2}$ & $3.0 \pm 0.6$ & $10.4 \pm 1.9$ & $2.7 \pm 0.4^{\mathrm{b}}$ & $8.6 \pm 1.8^{\mathrm{a}}$ \\
\hline PVR, Woods units ${ }^{\mathrm{c}}$ & $1.3 \pm 0.6$ & $1.3 \pm 0.3$ & $1.6 \pm 0.7^{\mathrm{d}}$ & $1.4 \pm 0.4^{\mathrm{d}}$ \\
\hline PVRi, Woods unitsc/m² & $2.6 \pm 1.1$ & $2.5 \pm 0.6$ & $2.7 \pm 1.2$ & $2.4 \pm 0.8$ \\
\hline$\alpha, \% / \mathrm{mm} \mathrm{Hg}$ & $2.0 \pm 1.5$ & $0.9 \pm 0.4$ & $2.3 \pm 1.9$ & $1.4 \pm 1.1^{\mathrm{b}}$ \\
\hline
\end{tabular}

Data are presented as mean \pm SD. The average age in both the male and female group was similar, with 11 women and 14 men $\geq 50$ years old. $\mathrm{CO}=$ cardiac output; $\mathrm{LAP}=$ left atrial pressure; $\mathrm{mPAP}=$ mean pulmonary artery pressure; $\mathrm{PVR}=$ pulmonary vascular resistance; $\mathrm{PVRi}=\mathrm{indexed}$ pulmonary vascular resistance; $\alpha=$ distensibility coefficient.

${ }^{a} P<.001$ compared with men.

b $P<.01$ compared with men.

'Or $\mathrm{mm} \mathrm{Hg} / \mathrm{min} / \mathrm{L}$.

dP $<.05$ compared with men.

described by a linear approximation, with average correlation coefficients of 0.92 and an SD of 0.08 . The average slope of mPAP-CO was $1.51 \pm 0.54 \mathrm{~mm} \mathrm{Hg} / \mathrm{L} / \mathrm{min}$. After Poon adjustment, the average slope of a line best fit to pooled data was $1.46 \mathrm{~mm} \mathrm{Hg} / \mathrm{L} / \mathrm{min}$ and the intercept $8 \mathrm{~mm} \mathrm{Hg}$. The mPAP-CO relationships were actually slightly curvilinear and, accordingly, also well fitted by the distensibility equation. The average distensibility coefficient $\alpha$ was $1.3 \% \pm 1.0 \% / \mathrm{mm} \mathrm{Hg}$ but it decreased by approximately $50 \%$ from rest to maximal exercise.

The limits of normal of the slopes of multipoint mPAP-CO relationships calculated as mean $-2 \mathrm{SD}$ to mean $+2 \mathrm{SD}$ were 0.5 to $2.5 \mathrm{~mm} \mathrm{Hg} / \mathrm{L} / \mathrm{min}$. Limits of normal of prediction bands for mPAP-CO relationships are shown in Figure 1. This presentation shows that the upper limit of normal of mPAP would be
$34 \mathrm{~mm} \mathrm{Hg}$ at a $\mathrm{CO}$ below $10 \mathrm{~L} / \mathrm{min}, 40 \mathrm{~mm} \mathrm{Hg}$ at a $\mathrm{CO}$ of $15 \mathrm{~L} / \mathrm{min}, 45 \mathrm{~mm} \mathrm{Hg}$ at a $\mathrm{CO}$ of $20 \mathrm{~L} / \mathrm{min}$, and $52 \mathrm{~mm} \mathrm{Hg}$ at a $\mathrm{CO}$ of $30 \mathrm{~L} / \mathrm{min}$.

$\mathrm{CO}$ was expectedly correlated to workload. However, as illustrated in Figure 2, there was a wide range of CO for any given level of workload.

\section{Sex Differences}

Comparisons between male and female subjects are presented in Tables 1 and 2. The men and women were of a similar average age, and the women had a lower body surface area. Resting MPAP was the same, but both $\mathrm{CO}$ and cardiac index were higher in men, whereas PVR, not indexed PVR, was higher in women (Table 1). The upper limit of normal of resting mPAP calculated as mean mPAP $+2 \mathrm{SD}$ was $21 \mathrm{~mm} \mathrm{Hg}$ in
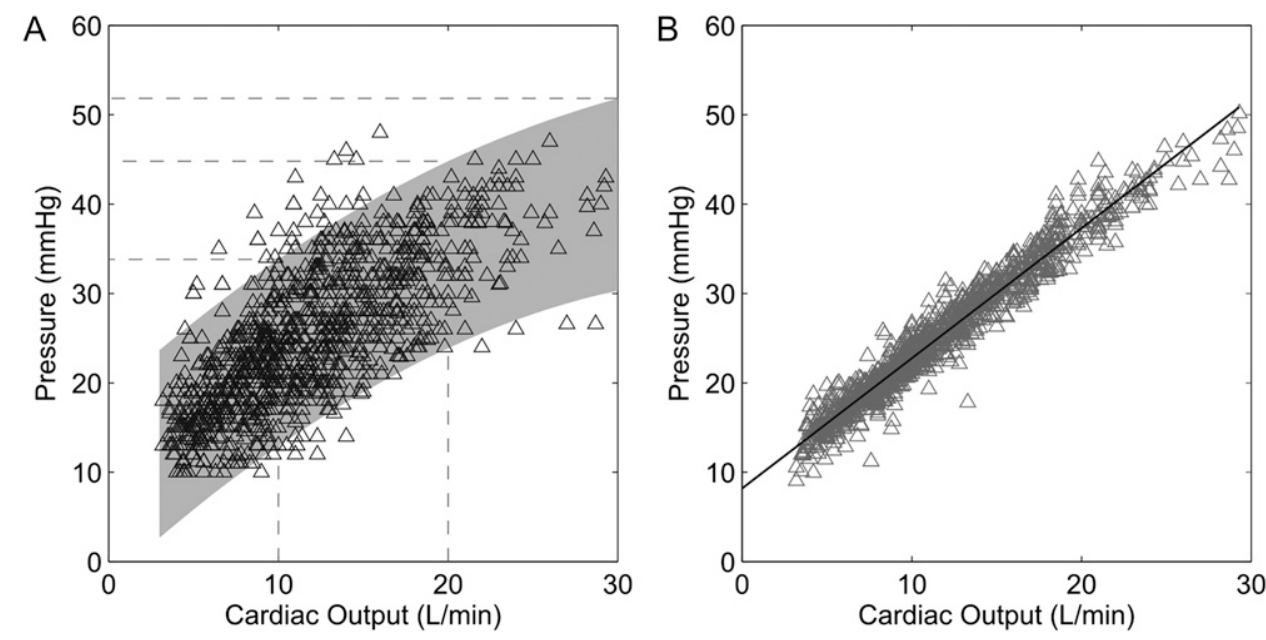

FIGURE 1. A, Mean pulmonary artery pressure (mPAP)-cardiac output (CO) relationships at rest and at progressively increased workloads. The prediction band is shown by the shaded area. mPAPs at CO values of 10,20 , and $30 \mathrm{~L} / \mathrm{min}$ are shown by the stippled lines. B, Poon-adjusted linear fit of the data points to recover a "normal" slope of $1.46 \mathrm{~mm} \mathrm{Hg} / \mathrm{L} / \mathrm{min}$. 


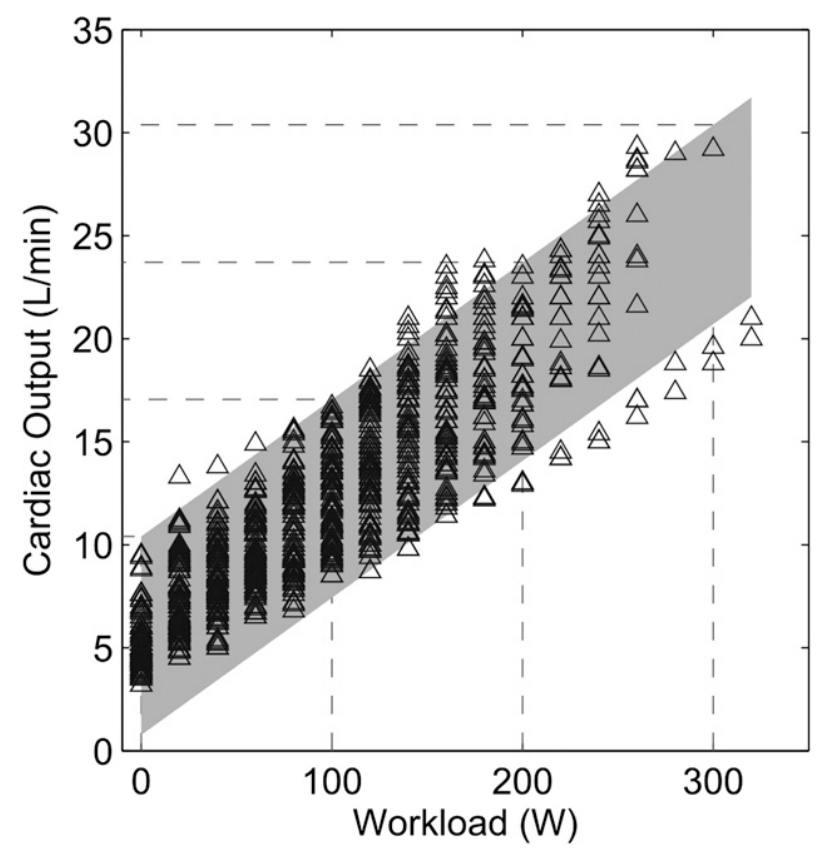

Figure 2. CO vs workload relationships at exercise. There is a wide range of $\mathrm{CO}$ values at any given workload. See Figure 1 legend for expansion of abbreviation.

both men and women. At peak exercise, men achieved higher maximal workload, CO, cardiac index, and mPAP, whereas PVR or indexed PVR were not different. There was a slight increase in LAP, by an average of $2 \mathrm{~mm} \mathrm{Hg}$, at maximal exercise, which was not different in women and in men. The upper limits of normal of $\mathrm{mPAP}$ at exercise were $48 \mathrm{~mm} \mathrm{Hg}$ in men and $45 \mathrm{~mm} \mathrm{Hg}$ in women. mPAP-CO or mPAP-cardiac index relationships were not different between men and women (Table 2). This was confirmed by the slopes of the linear fit to the Poon-adjusted mPAP-CO and mPAP-cardiac index data (Fig 3). As also shown in Table 1, sex had no measurable effect on $\alpha$ at rest, but at peak exercise $\alpha$ was significantly less in men.

Table 2-Characteristics of 56 Male and 57 Female Subjects

\begin{tabular}{lcc}
\hline \hline Variable & Men & Women \\
\hline Age, y & $38 \pm 14$ & $37 \pm 13$ \\
BSA, m ${ }^{2}$ & $2.0 \pm 0.1$ & $1.7 \pm 0.1^{\text {a }}$ \\
$\mathrm{mPAP}-\mathrm{CO}, \mathrm{mm} \mathrm{Hg} / \mathrm{L} / \mathrm{min}$ & $1.46 \pm 0.48$ & $1.55 \pm 0.60$ \\
$\mathrm{mPAP}-\mathrm{cardiac}$ index, $\mathrm{mm} \mathrm{Hg} / \mathrm{L} / \mathrm{min} / \mathrm{m}^{2}$ & $2.9 \pm 0.9$ & $2.6 \pm 1$ \\
Poon mPAP-CO, $\mathrm{mm} \mathrm{Hg} / \mathrm{L} / \mathrm{min}$ & 1.40 & 1.51 \\
$\alpha, \% / \mathrm{mm} \mathrm{Hg}$ & $1.1 \pm 0.6$ & $1.6 \pm 1.3^{\mathrm{b}}$ \\
$\quad<50$ y & $1.0 \pm 0.6$ & $1.7 \pm 1.4^{\mathrm{a}}$ \\
$\quad \geq 50$ y & $1.1 \pm 0.6$ & $1.0 \pm 0.3$ \\
Maximal workload, $W$ & $198 \pm 54$ & $153 \pm 34^{\mathrm{a}}$ \\
\hline
\end{tabular}

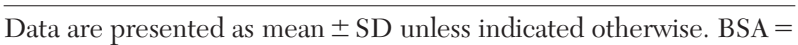
body surface area. See Table 1 for expansion of other abbreviations. aP $<.001$ compared with men.

b $P<.01$ compared with men.
In the women, $\alpha$ decreased as a function of age $\left(-0.025 \% / \mathrm{mm} \mathrm{Hg} / \mathrm{y}, R^{2}=0.07\right)$, down to values indiscernible from men at $\geq 50$ years (Table 2 ).

\section{Age Differences}

Twenty-five subjects, 11 women and 14 men, were $\geq 50$ years old. Their characteristics and hemodynamic measurements, compared with those of subjects $<50$ years old, are presented in Tables 3 and 4 . Older subjects had slightly higher mPAP and LAP at rest, lower maximal workload and cardiac index, steeper slopes of mPAP-CO or mPAP-cardiac index plots, and a trend to lower $\alpha$. PVR was not different. Steeper slopes of Poon-adjusted mPAP-cardiac index relationships in older subjects are illustrated in Figure 4.

\section{Discussion}

The results show that the upper limits of normal for mPAP at stress echocardiography depend on the achieved maximal CO. The previously used cut-off value of $30 \mathrm{~mm} \mathrm{Hg}$ for the diagnosis of exerciseinduced pulmonary hypertension is accurate for a CO below 8 to $10 \mathrm{~L} / \mathrm{min}$. Higher upper limits of normal for exercise $\mathrm{mPAP}$, up to $50 \mathrm{~mm} \mathrm{Hg}$, are to be considered for higher COs achieved by fit healthy subjects. The results also show, we believe for the first time, that there are no sex differences in PVR, but there is a higher pulmonary vascular distensibility in women $<50$ years old. Limited data on a small subgroup of subjects $\geq 50$ years old reveal expected steeper pulmonary vascular pressure-flow relationships and decreased distensibility.

Exercise stress echocardiographic measurements of the pulmonary circulation are usually reported as single SPAP estimates with or without mention of the achieved workload. This approach has indicated a higher prevalence of higher-than-normal exercise sPAP in the relatives of patients with pulmonary arterial hypertension as compared with control subjects. ${ }^{14}$ In these studies, the upper limit of normal of sPAP at exercise was estimated to be around $40 \mathrm{~mm} \mathrm{Hg}$. However, the same upper limit of normal has been determined for resting aging and overweight subjects ${ }^{15}$ or resting young adult athletes. ${ }^{16}$ This could be explained by altered left ventricular diastolic function with aging and obesity ${ }^{15}$ and by increased stroke volume as a result of training. ${ }^{16}$ It has long been believed that pulmonary artery pressure (PAP) does not increase much with exercise, so that an mPAP > $30 \mathrm{~mm} \mathrm{Hg}$ (corresponding to an sPAP of $47 \mathrm{~mm} \mathrm{Hg}^{10}$ ) at exercise would definitely be diagnostic of pulmonary vascular disease. ${ }^{2}$ However, mPAP increases at high levels of exercise, up to values of around 40 to $50 \mathrm{~mm} \mathrm{Hg}$ as reported in invasive $^{4,17}$ as well as noninvasive studies. ${ }^{7,18}$ In the 
A

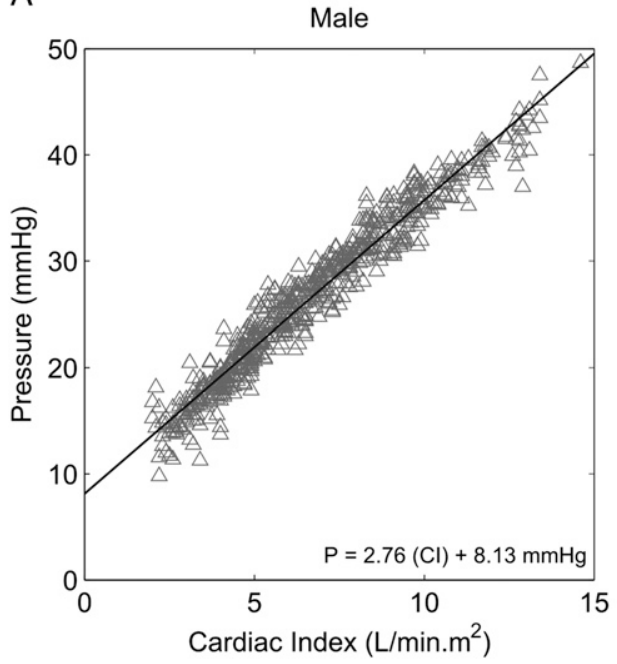

B

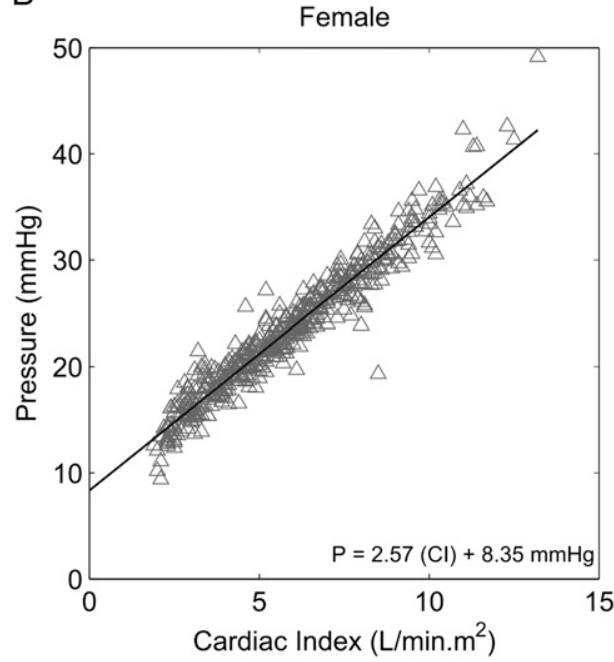

Figure 3. Poon-adjusted mPAP as a function of cardiac index at rest and at progressively increased workloads in healthy subjects. Sex had no effect on the slopes of the relationships. A, Men. B, Women. $\mathrm{CI}=$ cardiac index. See Figure 1 legend for expansion of other abbreviation.

present study on healthy young to middle-aged adults of variable fitness, the upper limit of normal of mPAP at exercise was $52 \mathrm{~mm} \mathrm{Hg}$. Because mPAP-CO relationships are close to linear, ${ }^{17}$ these observations underscore the need to express maximal exercise mPAP measurements as a function of CO. An alternative option is to normalize mPAP for workload. However, even though there is an obligatory relationship between $\mathrm{CO}$ and muscular work, the present results show that any given level of workload is associated with a wide range of flows. Because it is flow, rather than workload, that determines pulmonary vascular pressures, expressing the pulmonary vascular response to exercise as mPAP-CO relationships is preferable.

Echocardiographic estimates of pulmonary vascular pressures and CO are advantageous because they are noninvasive and flexible but have to rely on a series of assumptions in the calculations of vascular pressures and volume flows. Quality control studies have reported a disappointingly poor agreement between sPAP estimated from the maximal velocity of tricuspid regurgitation and invasive measurements at right-sided heart catheterization. ${ }^{19} \mathrm{CO}$ calculated from the left ventricular outflow tract dimension and velocity-time integral tends to be underestimated, mainly because of the underestimation of left ventricular outflow tract dimensions. ${ }^{8}$ However, although this is not proof, it may be noted that in the present study the Doppler echocardiographic measurements of $\mathrm{mPAP}$ and $\mathrm{CO}$ were in good agreement with previous invasive studies at any given level of workload., 47 They even allowed for the calculation of expected $\alpha$ distensibility coefficients in the range of $1 \%$ to $2 \% / \mathrm{mm} \mathrm{Hg},{ }^{13}$ which would not occur by chance or in the presence of too-large

Table 3-Hemodynamic Measurements at Rest and at Peak Exercise of 25 Subjects $\geq 50$ Years Old Compared With 88 Subjects $<50$ Years Old

\begin{tabular}{|c|c|c|c|c|}
\hline \multirow[b]{2}{*}{ Characteristic } & \multicolumn{2}{|c|}{$<50 \mathrm{y}$} & \multicolumn{2}{|c|}{$\geq 50 \mathrm{y}$} \\
\hline & Rest & Peak Exercise & Rest & Peak Exercise \\
\hline mPAP, mm Hg & $14.9 \pm 2.5$ & $32.4 \pm 7.4$ & $17.0 \pm 3.0^{\mathrm{a}}$ & $35.9 \pm 5.3^{b}$ \\
\hline $\mathrm{LAP}, \mathrm{mm} \mathrm{Hg}$ & $7.7 \pm 1.3$ & $9.5 \pm 1.3$ & $9.0 \pm 1.0^{\mathrm{a}}$ & $11.0 \pm 0.8^{\mathrm{a}}$ \\
\hline $\mathrm{CO}, \mathrm{L} / \mathrm{min}$ & $5.2 \pm 1.4$ & $18.1 \pm 4.9$ & $5.2 \pm 1.1$ & $16.0 \pm 3.2 \mathrm{c}$ \\
\hline Cardiac index, $\mathrm{L} / \mathrm{min} / \mathrm{m}^{2}$ & $2.85 \pm 0.56$ & $9.8 \pm 2.1$ & $2.77 \pm 0.57$ & $8.5 \pm 1.5^{\mathrm{a}}$ \\
\hline PVR, Woods units ${ }^{\mathrm{d}}$ & $1.42 \pm 0.59$ & $1.28 \pm 0.35$ & $1.61 \pm 0.83$ & $1.61 \pm 0.47^{\mathrm{a}}$ \\
\hline PVRi, Woods units $/ \mathrm{m}^{2}$ & $2.6 \pm 1.0$ & $2.3 \pm 0.6$ & $3.0 \pm 1.5$ & $3.0 \pm 0.8^{\mathrm{a}}$ \\
\hline$\alpha, \% / \mathrm{mm} \mathrm{Hg}$ & $2.2 \pm 1.8$ & $1.3 \pm 0.9$ & $2.0 \pm 1.7$ & $0.9 \pm 0.3$ \\
\hline
\end{tabular}

See Table 1 for expansion of abbreviations.

${ }^{a} P<.001$ compared with subjects $<50$ years old.

${ }^{\mathrm{b}} \mathrm{P}<.05$ compared with subjects $<50$ years old.

${ }^{c} P<.01$ compared with subjects $<50$ years old.

dOr $\mathrm{mm} \mathrm{Hg} / \mathrm{min} / \mathrm{L}$. 
Table 4-Characteristics of 25 Subjects $\geq 50$ Years Old Compared With 88 Subjects $<50$ Years Old

\begin{tabular}{lcc}
\hline \hline & \multicolumn{2}{c}{ Age } \\
\cline { 2 - 3 } Variable & $<50 \mathrm{y}$ & $\geq 50 \mathrm{y}$ \\
\hline Age, $\mathrm{y}$ & $32 \pm 9$ & $57 \pm 4^{\mathrm{a}}$ \\
$\mathrm{BSA}, \mathrm{m}^{2}$ & $1.82 \pm 0.2$ & $1.88 \pm 0.14^{\mathrm{b}}$ \\
$\mathrm{mPAP}-\mathrm{CO}, \mathrm{mm} \mathrm{Hg} / \mathrm{L} / \mathrm{min}$ & $1.40 \pm 0.46$ & $1.88 \pm 0.65^{\mathrm{a}}$ \\
$\mathrm{mPAP}-\mathrm{cardiac}$ index, & $2.5 \pm 0.8$ & $3.5 \pm 1.2^{\mathrm{a}}$ \\
$\quad$ mm Hg/L/min/m ${ }^{2}$ & $8.2 \pm 4.0$ & $7.4 \pm 5.0$ \\
Intercept & $1.4 \pm 1.1$ & $1.1 \pm 0.5$ \\
$\alpha, \% / \mathrm{mm} H g$ & $180 \pm 49$ & $159 \pm 53^{\mathrm{b}}$ \\
Maximal workload, W & &
\end{tabular}

See Tables 1 and 2 for expansion of abbreviations.

a $P<.001$ compared with subjects $<50$ years old.

${ }^{\mathrm{b}} \mathrm{P}<.05$ compared with subjects $<50$ years old.

errors on measurements. The weakest measurement from a methodologic point of view in the present study would probably be LAP estimated from an $\mathrm{E} / \mathrm{E}^{\prime}$ ratio, which could explain why LAP did not increase at the highest level of exercise, as expected. ${ }^{17}$ Previous validation studies of $\mathrm{E} / \mathrm{E}^{\prime}$ to estimate LAP or wedged PAP reported excessively high cardiac indexes ${ }^{11}$ and an absence of linear relationship between $\mathrm{E} / \mathrm{E}^{\prime}$ and wedged PAP at exercise. ${ }^{20}$ However, wedged PAP has also been shown to correlate poorly with left ventricular end-diastolic pressures, ${ }^{21}$ so invasively measured wedged PAP might not be an optimal gold standard for noninvasive estimates of LAP. Furthermore, mPAP-CO relationships at exercise show little change in LAP up to CO around $20 \mathrm{~L} / \mathrm{min}$, but a steep increase at higher $\mathrm{CO}$, which is delayed to even higher $\mathrm{CO}$ in the most fit subjects. ${ }^{22}$ Thus, only a mild increase in LAP by an average of $2 \mathrm{~mm} \mathrm{Hg}$ from rest to maximal exercise in the present study is not unexpected. It may be added that LAP is part of the $\alpha$ distensibility calculations, which yielded the expected range of values. $^{13}$

Because pulmonary vascular pressures are flow dependent, ${ }^{17}$ we defined the resistive properties of the pulmonary circulation by multipoint mPAP-CO or mPAP-cardiac index relationships. This approach has been shown repeatedly to allow for improved definition of PVR ${ }^{23}$ We confirmed previously reported high levels of linear correlations between mPAP and flow at exercise, so these relationships could reasonably be described by linear approximations. ${ }^{17}$ Previously calculated mean slopes of mPAP-CO were of $1 \mathrm{~mm} \mathrm{Hg} / \mathrm{L} / \mathrm{min}$ in young adults, increasing to $2.5 \mathrm{~mm} \mathrm{Hg} / \mathrm{L} / \mathrm{min}$ in advanced age. The average slopes of mPAP-CO relationships in the present study on middle-aged adults stabilized at $1.5 \mathrm{~mm} \mathrm{Hg} / \mathrm{L} / \mathrm{min}$ and, thus, were in keeping with these previous estimates from invasive measurements. However, because pulmonary resistive vessels are distensible, multipoint mPAP-CO plots are actually slightly curvilinear. ${ }^{13} \mathrm{It}$ is possible to calculate a distensibility coefficient $\alpha$ accounting for the recovered curvilinearity of mPAP-CO. Using a realistic distensibility model of the pulmonary circulation, an $\alpha$ value of approximately $2 \% / \mathrm{mm} \mathrm{Hg}$ has been calculated previously from invasive measurements in young adult volunteers. A distensibility $\alpha$ of the same order of magnitude was calculated from the present noninvasive determinations, confirming the previous report. ${ }^{7}$ It is of interest that $\alpha$ decreased by approximately $50 \%$ from rest to exercise, in keeping with the notion that pulmonary
A

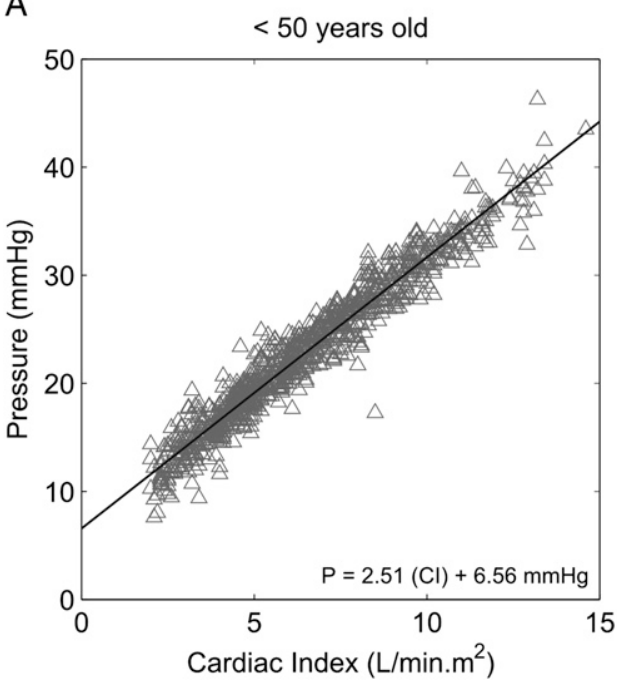

B

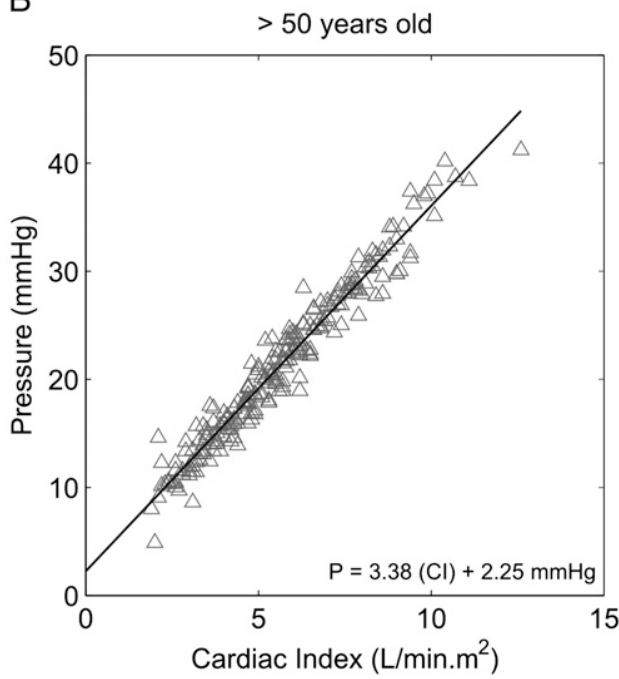

Figure 4. Poon-adjusted mPAP as a function of cardiac index at rest and at progressively increased workloads in healthy subjects. Aging was associated with an increased slope of the relationships. A, $<50$ years. $\mathrm{B}, \geq 50$ years. See Figure 1 and 3 legends for expansion of abbreviations. 
vascular compliance decreases along with increased distending pressures.

Previous exhaustive reviews of invasive pulmonary hemodynamic studies failed to uncover sex differences. This may be explained by the relatively small number of reported individual exercise measurements and the limited variable levels of workload and $\mathrm{CO}$, making isoflow comparisons difficult. ${ }^{4,17}$ In the present study, the linear approximations of pulmonary vascular pressure flow relationships were not different in men and women. However, when the pressure-flow coordinates were fitted to a distensibility model of the pulmonary circulation, it became apparent that women below the age of 50 years present with a higher pulmonary vascular compliance. In the present study, $\alpha$ was $45 \%$ higher in women than in men, but the sex difference disappeared in subjects $\geq 50$ years old.

$\mathrm{CO}$ was lower in women than in men in the present study, which is in agreement with previous invasive measurements. ${ }^{4,17}$ Somewhat surprisingly, the difference persisted after correction for body size. Recent MRI measurements confirmed a lower CO in women, but this sex difference was not any more significant when corrected for body size, with a cardiac index around $3.0 \mathrm{~L} / \mathrm{min} / \mathrm{m}^{2}$ for men and $2.8 \mathrm{~L} / \mathrm{min} / \mathrm{m}^{2}$ for women. ${ }^{24,25}$ However, in these studies, body sizecorrected right ventricular volume and mass were lower in women. ${ }^{24,25}$ The present results suggest that this may be due to the lower afterload of a more distensible pulmonary circulation.

The exercise stress tests were performed in a semirecumbant position. Previous invasive studies reported a higher resting PVR in the upright, compared with recumbent, position, because of gravity-dependent lower venous return leading to pulmonary vascular derecruitment. However, the difference disappeared with exercise, in relation to increased pulmonary blood flow and full vascular recruitment. Accordingly, multipoint mPAP-CO relationships were not affected by body position. ${ }^{17}$ It is, therefore, unlikely that body position would have affected the stress echocardiographyderived pulmonary vascular pressure-flow relationships.

Our study was not designed to study the effects of aging on the pulmonary circulation. However, in 25 of the 113 subjects aged $\geq 50$ years old, the slope of mPAP-cardiac index was increased and $\alpha$ was decreased, confirming previous estimations., ${ }^{4,13,17}$ The group of subjects $\geq 50$ years old was too small, with the oldest subject aged 63 years, to allow for estimations of limits of normal as a function of increased aging. Nevertheless, it is remarkable that the present noninvasive measurements uncovered the expected effects of aging on resistive and distensibility properties of the pulmonary circulation.

There are several additional limitations to the present study. The recovery rate of $87 \%$ of sufficient-quality signals at the echocardiography of the pulmonary circulation of normal subjects is unusually high and is probably explained by high levels of previous training and the dedication of the investigators. Lower recovery rates may be expected in daily clinical practice. Furthermore, there was no validation against gold standard invasive measurements. However, this would be ethically and practically very difficult to obtain in a large number of healthy subjects. Finally, the study was performed in a single center and, thus, would require confirmation in a multicentric fashion.

In summary, the present results offer flow-corrected upper limits of normal of PAPs at exercise stress echocardiography that are in compatible with previous invasive measurements. The results also show that women have a more distensible pulmonary circulation, which is likely estrogen related. It is hoped that improved definition of the limits of normal of exercise stress echocardiography estimates of pulmonary vascular pressures and $\mathrm{CO}$ will help make the method useful for the early diagnosis of pulmonary hypertension.

\section{ACKNOWLEDGMENTS}

Author contributions: Dr Argiento: contributed to the original design and concept of the study, data acquisition, data analysis, and preparation and critical review of the manuscript.

Dr Vanderpool: contributed to the analysis and interpretation of data and preparation and critical review of the manuscript.

Dr Mulè: contributed to the data acquisition, data analysis, review of echocardiographic images, and critical review of the manuscript. Dr Russo: contributed to the concept of the study and critical review of the manuscript.

Dr D'Alto: contributed to the review of the echocardiographic images and critical review of the manuscript.

Dr Bossone: contributed to the concept of the study and critical review of the manuscript.

Dr Chesler: contributed to the data analysis and critical review of the manuscript.

Dr Naeije: contributed to the overall design and concept of the study, analysis and interpretation of data, and preparation and critical review of the manuscript.

Financial/nonfinancial disclosures: The authors have reported to CHEST that no potential conflicts of interest exist with any companies/organizations whose products or services may be discussed in this article.

Role of sponsors: The sponsors had no role in the design of the study, the collection and analysis of the data, or in the preparation of the manuscript.

Other contributions: This work was performed at the Free University of Brussels, Brussels, Belgium.

\section{REFERENCES}

1. Naeije R. In defence of exercise stress tests for the diagnosis of pulmonary hypertension. Heart. 2011;97(2):94-95.

2. Rubin LJ. Primary pulmonary hypertension. N Engl J Med. 1997;336(2):111-117.

3. Badesch DB, Champion HC, Sanchez MA, et al. Diagnosis and assessment of pulmonary arterial hypertension. J Am Coll Cardiol. 2009;54(suppl 1):S55-66. 
4. Kovacs G, Berghold A, Scheidl S, Olschewski H. Pulmonary arterial pressure during rest and exercise in healthy subjects: a systematic review. Eur Respir J. 2009;34(4):888-894.

5. Tolle JJ, Waxman AB, Van Horn TL, Pappagianopoulos PP, Systrom DM. Exercise-induced pulmonary arterial hypertension. Circulation. 2008;118(21):2183-2189.

6. Lau EMT, Manes A, Celermajer DS, Galiè N. Early detection of pulmonary vascular disease in pulmonary arterial hypertension: time to move forward. Eur Heart J. 2011;32(20): 2489-2498.

7. Argiento $\mathrm{P}$, Chesler N, Mulè M, et al. Exercise stress echocardiography for the study of the pulmonary circulation. Eur Respir J. 2010;35(6):1273-1278.

8. Christie J, Sheldahl LM, Tristani FE, Sagar KB, Ptacin MJ, Wann S. Determination of stroke volume and cardiac output during exercise: comparison of two-dimensional and Doppler echocardiography, Fick oximetry, and thermodilution. Circulation. 1987;76(3):539-547.

9. Yock PG, Popp RL. Noninvasive estimation of right ventricular systolic pressure by Doppler ultrasound in patients with tricuspid regurgitation. Circulation. 1984;70(4):657-662.

10. Chemla D, Castelain V, Humbert M, et al. New formula for predicting mean pulmonary artery pressure using systolic pulmonary artery pressure. Chest. 2004;126(4):1313-1317.

11. Nagueh SF, Middleton KJ, Kopelen HA, Zoghbi WA, Quiñones MA. Doppler tissue imaging: a noninvasive technique for evaluation of left ventricular relaxation and estimation of filling pressures. J Am Coll Cardiol. 1997;30(6):1527-1533.

12. Poon CS. Analysis of linear and mildly nonlinear relationships using pooled subject data. J Appl Physiol. 1988;64(2):854-859.

13. Reeves JT, Linehan JH, Stenmark KR. Distensibility of the normal human lung circulation during exercise. Am J Physiol Lung Cell Mol Physiol. 2005;288(3):L419-425.

14. Grünig E, Weissmann S, Ehlken N, et al. Stress Doppler echocardiography in relatives of patients with idiopathic and familial pulmonary arterial hypertension: results of a multicenter European analysis of pulmonary artery pressure response to exercise and hypoxia. Circulation. 2009;119(13): 1747-1757.

15. McQuillan BM, Picard MH, Leavitt M, Weyman AE. Clinical correlates and reference intervals for pulmonary artery systolic pressure among echocardiographically normal subjects. Circulation. 2001;104(23):2797-2802.

16. D’Andrea A, Naeije R, D’Alto M, et al. Range in pulmonary artery systolic pressure among highly trained athletes. Chest. 2011;139(4):788-794

17. Reeves JT, Dempsey JA, Grover RF. Pulmonary circulation during exercise. In: Weir EK, Reeves JT, eds. Pulmonary Vascular Physiology and Physiopathology. New York, NY: Marcel Dekker; 1989:107-133.

18. Bossone E, Rubenfire M, Bach DS, Ricciardi M, Armstrong WF. Range of tricuspid regurgitation velocity at rest and during exercise in normal adult men: implications for the diagnosis of pulmonary hypertension. J Am Coll Cardiol. 1999;33(6): 1662-1666.

19. Fisher MR, Forfia PR, Chamera E, et al. Accuracy of Doppler echocardiography in the hemodynamic assessment of pulmonary hypertension. Am J Respir Crit Care Med. 2009; 179(7):615-621.

20. Talreja DR, Nishimura RA, Oh JK. Estimation of left ventricular filling pressure with exercise by Doppler echocardiography in patients with normal systolic function: a simultaneous echocardiographic-cardiac catheterization study. J Am Soc Echocardiogr. 2007;20(5):477-479.

21. Halpern SD, Taichman DB. Misclassification of pulmonary hypertension due to reliance on pulmonary capillary wedge pressure rather than left ventricular end-diastolic pressure. Chest. 2009;136(1):37-43.

22. Stickland MK, Welsh RC, Petersen SR, et al. Does fitness level modulate the cardiovascular hemodynamic response to exercise? J Appl Physiol. 2006;100(6):1895-1901.

23. McGregor M, Sniderman A. On pulmonary vascular resistance: the need for more precise definition. Am J Cardiol. $1985 ; 55(1): 217-221$.

24. Lorenz CH, Walker ES, Morgan VL, Klein SS, Graham TP Jr. Normal human right and left ventricular mass, systolic function, and gender differences by cine magnetic resonance imaging. J Cardiovasc Magn Reson. 1999;1(1):7-21.

25. Sandstede J, Lipke C, Beer M, et al. Age- and gender-specific differences in left and right ventricular cardiac function and mass determined by cine magnetic resonance imaging. Eur Radiol. 2000;10(3):438-442. 